\title{
EFEKTIFITAS PENGGUNAAN MEDIA PEMBELAJARAN E-LEARNING PADA MATA KULIAH QOWAIDULLUGHOH DI PRODI PAI FAI UHAMKA
}

\author{
Fitri Liza \\ Program Studi Pendidikan Agama Islam, Universitas Muhammadiyah Prof. Dr. HAMKA \\ Jakarta \\ Email : fitriliza70@gmail.co.id Hp ; 08131656532
}

\begin{abstract}
E-learning based learning media is technology based learning where learning material is presented in the form of audio visual such as video. This type of research is an experimental study to determine the effectiveness of learning media that is treated. The study population was all semester II PAI UHAMKA students in South Jakarta. The sample used in this study was taken randomly, namely the PAI classes A, B and C. The data collected included primary data. The results of this study were obtained from primary data. Primary data were obtained from pre-test and post-test results of students. There is an increase in the pre-test and post-test results in the experimental class and a decrease in the pre-test and post-test results in the control class. The average results obtained from the experimental class from 59.36 to 71.76 and in the control class from 72.82 to 70.64 . The difference in mean results shows an increase in pre-test and post-test results and it can be concluded that the e-learning-based learning media is effectively used in learning.

Keywords : Qowaidullugoh, BOZAMI, Media based Android, audio visual, effective learning
\end{abstract}

\begin{abstract}
Abstrak
Media pembelajaran berbasis e-learning merupakan pembelajaran berbasis teknologi di mana materi pembelajaran disajikan dalam bentuk audio visual seperti video dan lain-lain. Jenis penelitian ini adalah penelitian eksperimen untuk mengetahui keefektifan dari media pembelajaran yang ditreatment. Populasi penelitian adalah seluruh Mahasiswa PAI semester II UHAMKA Jakarta Selatan. Sampel yang dipakai dalam penelitian ini diambil secara random yaitu kelas PAI A, B dan C. Data yang dikumpulkan meliputi data primer. Hasil penelitian ini diperoleh dari data primer. Data primer diperoleh dari hasil pre tes dan post tes mahasiswa. Terdapat kenaikan dari hasil pre tes dan post tes di kelas eksperimen dan penurunan dari hasil pre tes dan post tes di kelas kontrol. Hasil rata-rata yang diperoleh kelas ekperimen dari 59.36 menjadi 71.76 dan pada kelas kontrol dari 72.82 menjadi 70.64. Perbedaan hasil ratarata tersebut menunjukkan peningkatan hasil pre tes dan post tes dan dapat ditarik kesimpulan bahwa media pembelajaran berbasis e-learning efektif dipakai dalam pembelajaran.
\end{abstract}




\section{Kata Kunci: Qowaidullugoh, BOZAMI, Media berbasis Android, audio visual, Pembelajaran yang efektif}

\section{PENDAHULUAN}

Perkembangan teknologi informasi membawa perubahan pada setiap aspek kehidupan manusia termasuk pendidikan. Pendidik sebagai garda terdepan dalam proses pembelajaran dituntut untuk mengikuti alur perkembangan ilmu pengetahuan dan teknologi agar mampu mencetak generasi-generasi yang dapat membawa perubahan untuk Indonesia yang lebih baik.

Pada tahun 2018, Asosiasi Penyelenggara Jasa Internet Indonesia (APJII) menemukan ada pertumbuhan jumlah pengguna internet, dari yang sebelumnya 143,26 juta menjadi 171,17 juta. Artinya, 64,8 \% dari total jumlah penduduk Indonesia sudah menggunakan internet. Kelompok umur yang paling mendominasi dalam penggunaan internet adalah usia 15-19 tahun hingga mencapai penetrasi paling tinggi yaitu $91 \%$. Asosiasi Penyelenggara Jasa Internet Indonesia (APJII) menyebutkan sehari pengguna internet dapat menghabiskan waktunya lebih dari 6 jam sehari (Haryanto, 2019).

Data di atas menunjukkan bahwa internet yang diperoleh melalui perantara smartphone menjadi kebutuhan primer setiap orang. Berita dan tampilan yang muncul di internet mencakup segala hal yang mampu mempengaruhi sikap dan pola pikir orang yang menggunakannya. Penggunaan internet yang berlebih mengakibatkan dampak negatif berupa efek samping yang cukup besar pada setiap lini kehidupan remaja, seperti sosial, klinis, akademis, ekonomis, dan agamis. (Hakim dan Raj, 2017). Kemudian muncul pertanyaan, apakah generasi muda Indonesia harus menutup mata atas perkembangan teknologi agar tidak terjerumus dengan hal-hal negatif di dunia maya?

Perlu diketahui bahwa penggunaan internet tidak hanya membawa dampak negatif, tetapi juga memiliki dampak positif. Dalam dunia pendidikan, hasil penelitian Nurmalasari dan Wulandari menyatakan bahwa ada hubungan penggunaan gadget dengan tingkat prestasi belajar siswa di SMPN Satu Atap Pakisjaya Karawang. (Nurmalasari dan Wulandari, 2018). Penelitian lain juga menunjukkan pengaruh penggunaan media $e$ learning berbasis quipper school terhadap minat belajar sebesar $40.3 \%$ dan pengaruhnya terhadap hasil belajar sebesar 27.5\%, sehingga penggunaan media pembelajaran sejarah $e$ learning berbasis quipper school mempunyai pengaruh terhadap minat dan hasil belajar 
siswa kelas X SMK N 04 Kendal. (Ratri, Bain dan Amin, 2017). Begitupula hasil penelitian yang dilakukan oleh Sumardana, bahwa hasil uji efektivitas diperoleh nilai rata pre-test $(54,33)$ lebih kecil dari nilai Post-test $(80,33)$. Hal ini berarti terdapat perbedaan yang signifikan antara hasil belajar IPA sebelum dan sesudah menggunakan media $e$ learning berbasis schoology. Dengan demikian dapat disimpulkan media e-learning berbasis schoology efektif untuk meningkatkan hasil belajar siswa pada mata pelajaran IPA kelas VIII di SMP Saraswati Singaraja tahun pelajaran 2016/2017. (Sumardana, 2016)

Menilik hasil penelitian terdahulu, maka pendidik harus mampu mengarahkan anak didik memanfaatkan internet untuk hal-hal yang positif. Salah satunya dengan menjadikan internet sebagai media pembelajaran. Istilah media mula-mula dikenal dengan alat peraga. Media pembelajaran dapat sebagai wadah penyalur pesan dalam proses pembelajaran. Media pembelajaran yang dirancang secara baik akan sangat membantu peserta didik dalam memahami materi pelajaran. Di era globalisasi dan informasi ini, perkembangan media pembelajaran juga semakin maju. Penggunaan Teknologi Informasi (TI) sebagai media pembelajaran sudah merupakan suatu tuntutan. Media pembelajaran berbasis TI dapat berupa internet, intranet, mobile phone, dan CD Room/Flash Disk. Adapun komponen utamanya meliputi Learning Management System (LMS), dan Learning Content (Muhson, 2010).

Dalam perkembangannya muncul istilah e-learning. Huruf "e" merupakan singkatan dari elektronik. Artinya media pembelajaran berupa alat elektronik, meliputi CD multimedia interaktif sebagai bahan ajar offline dan website sebagai bahan ajar online. Menurut Sumaharsono, penggunaan media memiliki manfaat untuk menimbulkan gairah belajar, interaksi lebih langsung antara murid dan sumber belajar serta belajar tidak dibatasi dengan ruang dan waktu. (Sumiharsono dan Hasanah, 2017).

Berdasarkan pemaparan tersebut, maka rumusan masalah, sebagai berikut. Bagaimanakah efektifitas penggunaan media pembelajaran e-learning pada mata kuliah Qowaidullughoh di Prodi PAI FAI UHAMKA? Maka tujuan penelitian ini untuk mengetahui efektifitas penggunaan media pembelajaran e-learning pada mata kuliah Qowaidullughoh di Prodi PAI FAI UHAMKA.

\section{METODE}


Metode yang digunakan dalam penelitian ini menggunakan metode penelitian kuantitatif dengan menggunakan jenis penelitian eksperimen dengan mengujicobakan model pembelajaran dengan aplikasi "BOZAMI" berbasis android. Populasi penelitian adalah seluruh mahasiswa PAI FAI UHAMKA Semester II. Sampel yang dipakai dalam penelitian ini kelas II B dan kelas IIC. Data yang dikumpulkan meliputi data primer. Data primer diperoleh dari pre test dan post test mahasiswa.

\section{Analisis Data}

Analisis data dalam penelitian ini dengan menggunakan excel dengan mentabulasi hasil intrumen yang diperoleh dari hasil pre test dan post test yang diisi oleh mahasiswa PAI FAI UHAMKA.

\section{HASIL DAN PEMBAHASAN}

Tabel 1. Hasil Skor Tes Awal (Pre test) Kelas Eksperimen dan Kelas Kontrol

\begin{tabular}{lcc}
\hline \multicolumn{1}{c}{ Nama } & $\begin{array}{c}\text { Jumlah } \\
\text { Mahasiswa }\end{array}$ & Rata-rata \\
\hline II B (Eksperimen) & 36 & 59,36 \\
II C (Kontrol) & 25 & 71,76 \\
Total & 61 & 132,2 \\
\hline
\end{tabular}

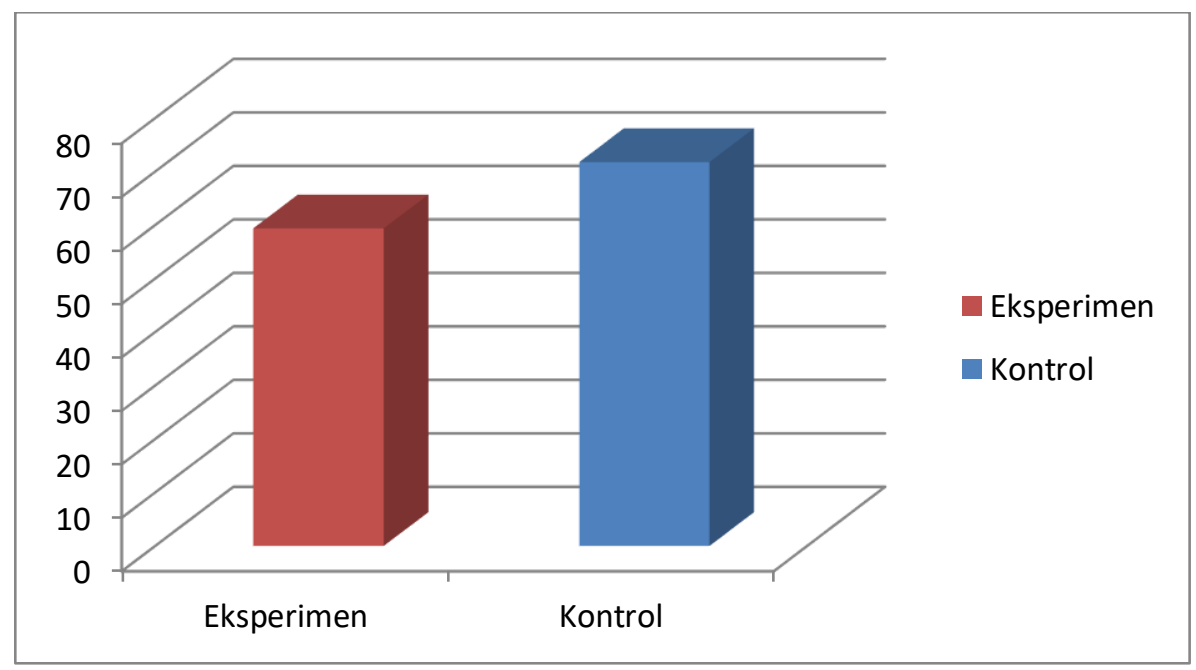

Gambar 1. Histogram Hasil Tes Awal (Pre test) Kelas Eksperimen dan Kelas Kontrol

Sebelum diujicobakan media pembelajaran BOZAMI, dilakukan pre test terlebih dahulu dan diolah hasil pre test masing-masing kelas kontrol dan eksperimen. Kelas 
eksperimen yaitu kelas II B dengan jumlah mahasiswa 36 orang sedangkan kelas control adalah kelas II C dengan jumlah mahasiswa 25 orang dan 6 orang saat pre test tidak hadir.

Dari table 1 di atas diperoleh hasil rata-rata perbandingan kelas eksperimen dan kelas kontrol pada mata kuliah Qowaidullugoh. Rata-rata kelas eksperimen memperoleh hasil 59,36 dan kelas kontrol memperoleh nilai rata-rata sebesar 71,76.

Tabel 2. Nilai awal (pre-test) kelas eksperimen

\begin{tabular}{cccc}
\hline No. & Nilai & Frekuensi (mahasiswa) & Persen (\%) \\
\hline 1. & 17 & 1 & $2,77 \%$ \\
2. & 20 & 1 & $2,77 \%$ \\
3. & 27 & 3 & $8,33 \%$ \\
4. & 40 & 4 & $11,11 \%$ \\
5. & 43 & 1 & $2,77 \%$ \\
6. & 50 & 2 & $5,55 \%$ \\
7. & 53 & 1 & $2,77 \%$ \\
8. & 57 & 2 & $5,55 \%$ \\
9. & 60 & 2 & $5,55 \%$ \\
10. & 63 & 1 & $2,77 \%$ \\
11. & 67 & 1 & $2,77 \%$ \\
12. & 70 & 8 & $22,22 \%$ \\
13. & 73 & 1 & $2,77 \%$ \\
14. & 77 & 2 & $5,55 \%$ \\
15. & 80 & 1 & $2,77 \%$ \\
16. & 83 & 3 & $8,33 \%$ \\
17. & 90 & 1 & $2,77 \%$ \\
18. & 93 & 1 & $2,77 \%$ \\
& Jumlah & 36 & $100 \%$ \\
\hline
\end{tabular}

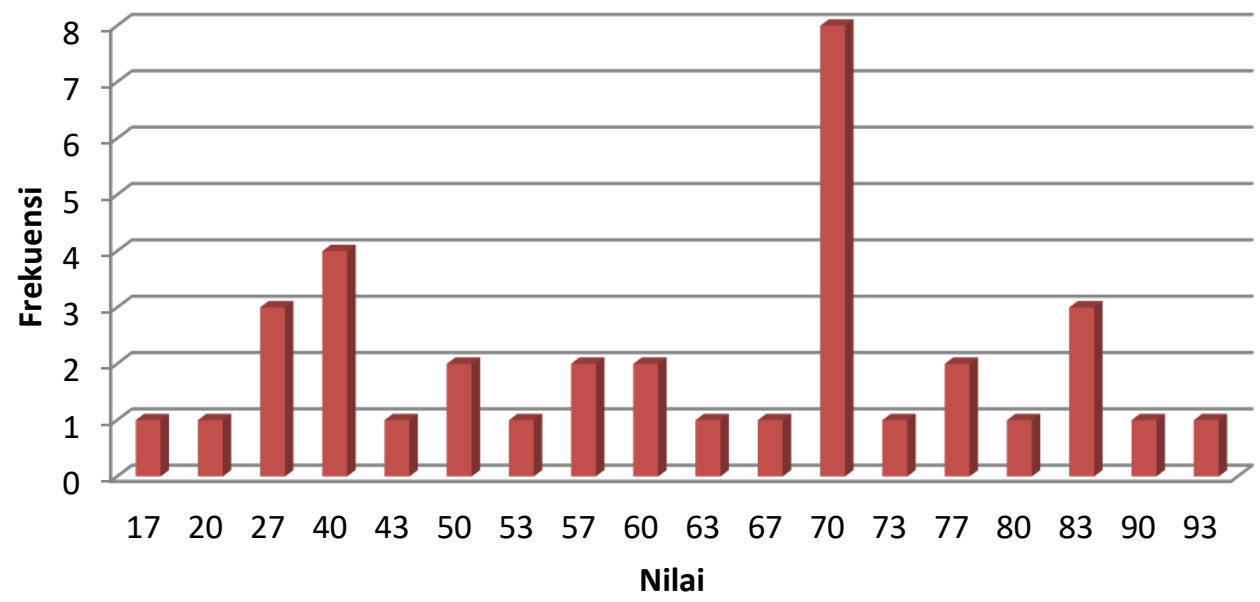

JURNAL PENDIDIKAN ISLAM Volume 10, Nomor 2, November 2019 


\section{Gambar 2. Histogram Hasil Tes Awal (Pre test) Kelas Eksperimen}

Dari tabel 2 di atas dapat diperoleh informasi bahwa hasil nilai pre test dari kelas eksperimen dengan angka terendah memperoleh nilai 17 dengan jumlah mahasiswa 1 orang dan nilai tertinggi 93 dengan jumlah 1 orang. Di mana nilai-nilai yang diperoleh dari 36 peserta dengan range mulai dari 17-93. Di mana modus atau nilai terbanyak yang diperoleh dari kelas eksperimen mendapat nilai 70 dengan jumlah frekuensi mahasiswa 8 orang. Nilai terendah 1 orang dan tertinggi sebanyak 1 orang.

Tabel 3. Nilai awal (pre-test) kelas kontrol

\begin{tabular}{|c|c|c|c|}
\hline No. & Nilai & Frekuensi (mahasiswa) & Persen (\%) \\
\hline 1. & 30 & 1 & $4 \%$ \\
\hline 2. & 37 & 2 & $8 \%$ \\
\hline 3. & 60 & 1 & $4 \%$ \\
\hline 4. & 63 & 2 & $8 \%$ \\
\hline 5. & 67 & 1 & $4 \%$ \\
\hline 6. & 70 & 1 & $4 \%$ \\
\hline 7. & 73 & 3 & $12 \%$ \\
\hline 8. & 77 & 3 & $12 \%$ \\
\hline 9. & 80 & 3 & $12 \%$ \\
\hline 10. & 83 & 2 & $8 \%$ \\
\hline 11. & 87 & 3 & $12 \%$ \\
\hline 12. & 90 & 2 & $8 \%$ \\
\hline 13. & 97 & 1 & $4 \%$ \\
\hline & Jumlah & 25 & $100 \%$ \\
\hline
\end{tabular}

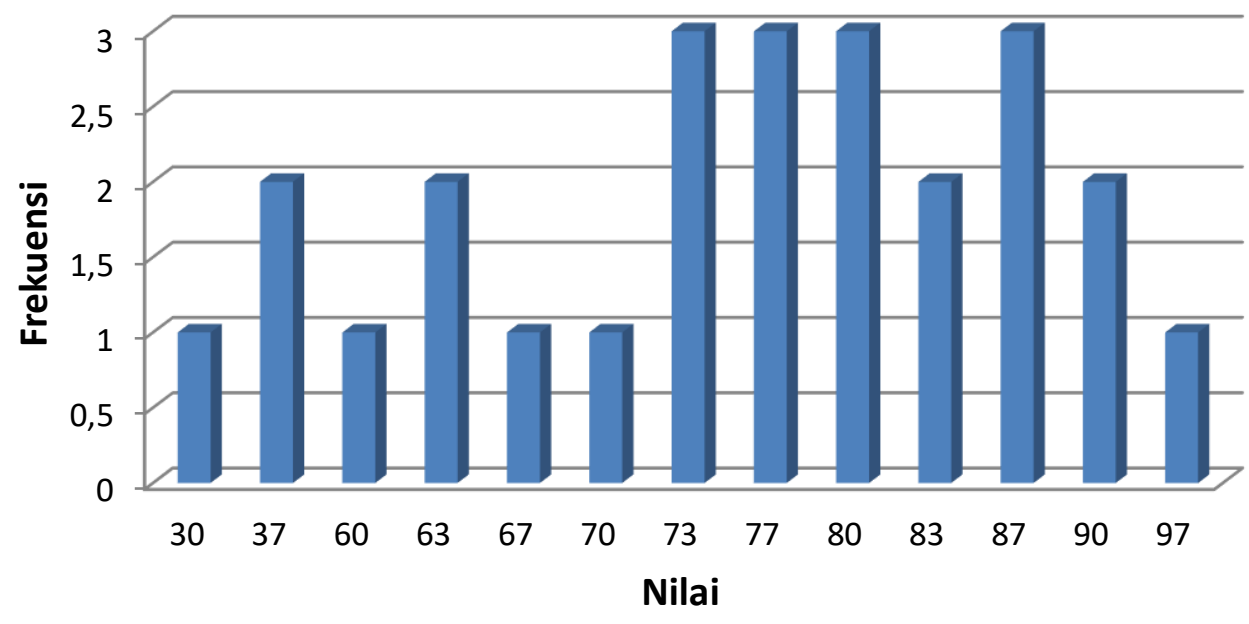




\section{Gambar 3. Histogram Hasil Tes Awal (Pre test) Kelas Kontrol}

Dari tabel 3 di atas dapat diperoleh informasi bahwa hasil nilai pre test dari kelas dengan angka terendah memperoleh nilai 30 dengan jumlah mahasiswa 1 orang dan nilai tertinggi 97 dengan jumlah 1 orang. Di mana nilai-nilai yang diperoleh dari 25 peserta dengan range mulai dari 30-97. Di mana modus atau nilai terbanyak yang diperoleh dari kelas eksperimen mendapat nilai 73, 77, 80 dan 87 dengan jumlah frekuensi mahasiswa 3 orang. Nilai terendah 1 orang dan tertinggi sebanyak 1 orang.

\section{Tabel 4. Hasil Tes Akhir (Post Test) Kelas Eksperimen dan Kelas Kontrol}

\begin{tabular}{lcc}
\hline \multicolumn{1}{c}{ Nama } & $\begin{array}{c}\text { Jumlah } \\
\text { Mahasiswa }\end{array}$ & Rata-rata \\
\hline II B (Eksperimen) & 26 & 72,84 \\
II C (Kontrol) & 25 & 70,64 \\
Total & 51 & 142,17 \\
\hline
\end{tabular}

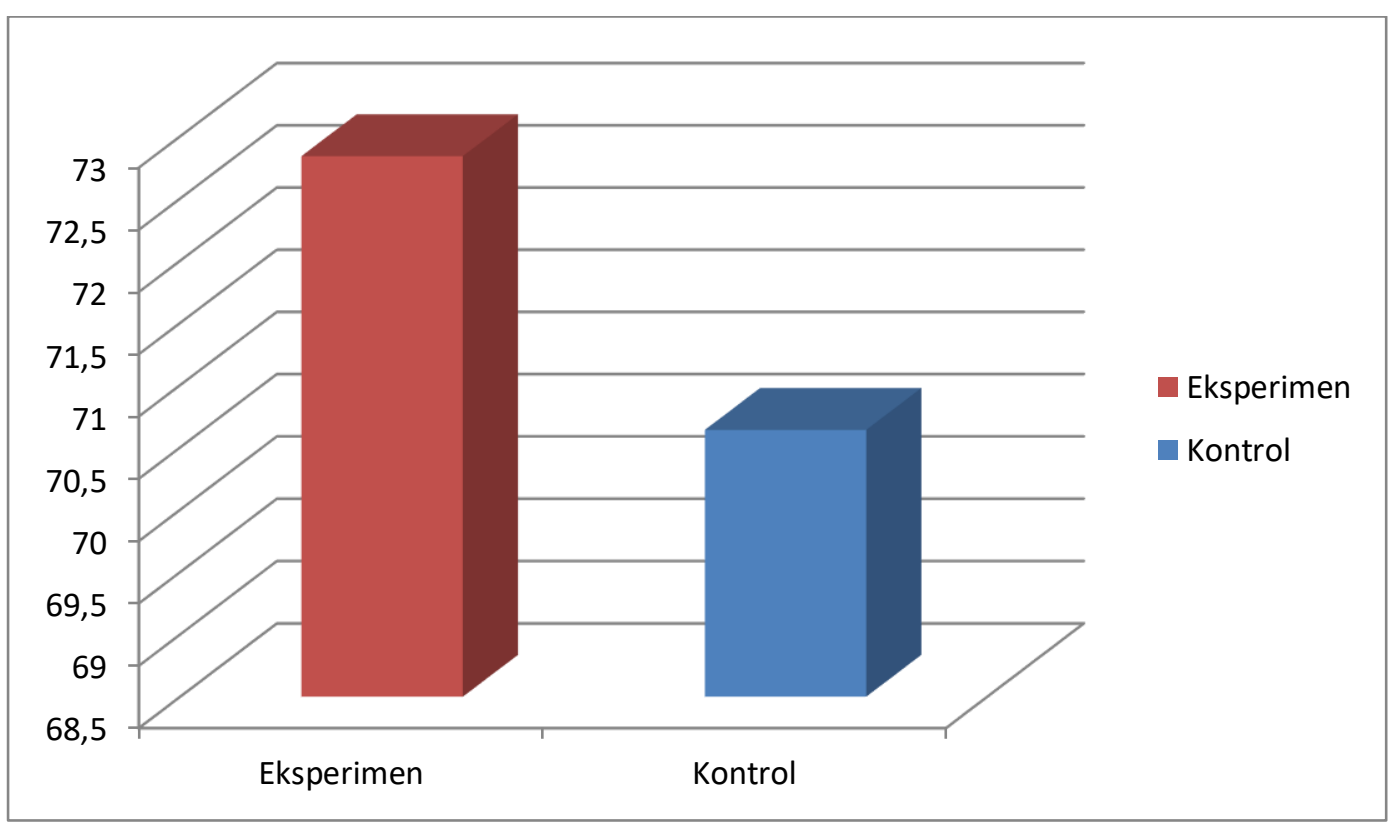

Gambar 4. Histogram Hasil Tes Akhir (Post Test) Kelas Eksperimen dan Kelas Kontrol 
Setelah diberi perlakuan saat kegiatan belajar mengajar dan diujicobakan media pembelajaran BOZAMI ini dilakukan post test kembali, dan diolah hasil post test masingmasing kelas kontrol dan eksperimen. Kelas eksperimen yaitu kelas II B dengan jumlah mahasiswa 26 orang dan 10 orang saat post test tidak hadir sedangkan kelas kontrol yaitu kelas II C dengan jumlah mahasiswa 25 orang dan 6 orang saat post test tidak hadir.

Dari tabel 4. di atas diperoleh hasil rata-rata hasil post test perbandingan kelas eksperimen dan kelas kontrol pada mata kuliah Qowaidullugoh. Rata-rata kelas eksperimen memperoleh hasil 72,84 dan kelas kontrol memperoleh nilai rata-rata sebesar 70,64.

Tabel 5. Nilai akhir (post-test) kelas eksperimen

\begin{tabular}{cccc}
\hline No. & Nilai & Frekuensi (mahasiswa) & Persen (\%) \\
\hline 1. & 33 & 1 & $3,84 \%$ \\
2. & 40 & 1 & $3,84 \%$ \\
3. & 43 & 1 & $3,84 \%$ \\
4. & 47 & 3 & $11,53 \%$ \\
5. & 53 & 1 & $3,84 \%$ \\
6. & 70 & 2 & $7,69 \%$ \\
7. & 73 & 1 & $3,84 \%$ \\
8. & 77 & 4 & $15,38 \%$ \\
9. & 80 & 2 & $7,69 \%$ \\
10. & 83 & 5 & $19,23 \%$ \\
11. & 87 & 1 & $3,84 \%$ \\
12. & 90 & 1 & $3,84 \%$ \\
13. & 93 & 2 & $7,69 \%$ \\
14. & 97 & 1 & $3,84 \%$ \\
& Jumlah & 26 & $100 \%$ \\
\hline
\end{tabular}




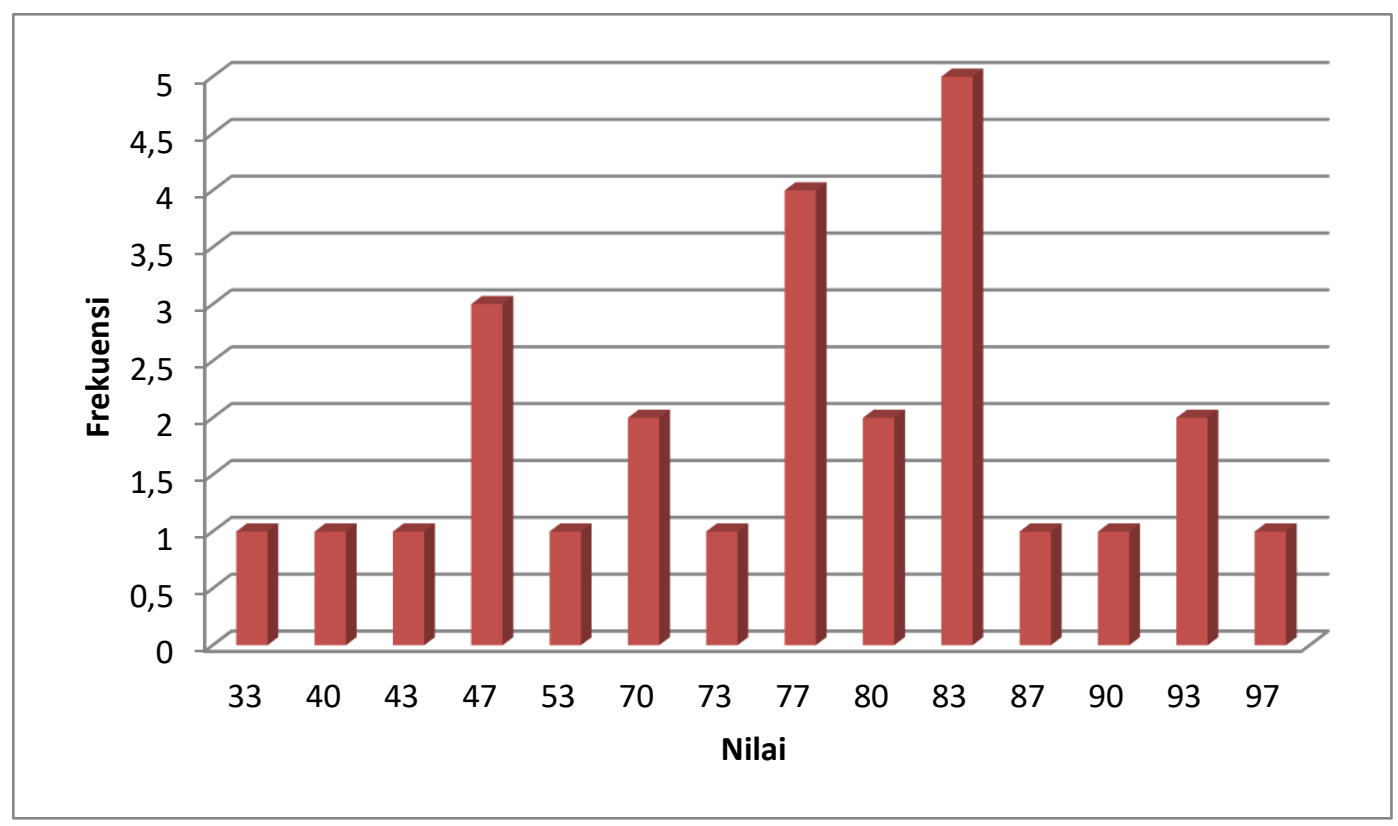

Gambar 5. Histogram Hasil Tes Akhir (Post Test) Kelas Eksperimen

Dari tabel 5 di atas dapat diperoleh informasi bahwa hasil nilai post test dari kelas eksperimen di mana angka terendah memperoleh nilai terendah 33 dengan jumlah mahasiswa 1 orang dan nilai tertinggi 97 dengan jumlah 1 orang. Di mana nilai-nilai yang diperoleh dari 26 peserta dengan range mulai dari 33-97. Di mana modus atau nilai terbanyak yang diperoleh dari kelas eksperimen mendapat nilai 83 dengan jumlah frekuensi mahasiswa 5 orang. Nilai terendah 1 orang dan tertinggi sebanyak 1 orang.

Tabel 6. Nilai akhir (post-test) kelas kontrol

\begin{tabular}{|c|c|c|c|}
\hline No. & Nilai & Frekuensi (mahasiswa) & Persen (\%) \\
\hline 1. & 33 & 1 & $4 \%$ \\
\hline 2. & 47 & 2 & $8 \%$ \\
\hline 3. & 60 & 1 & $4 \%$ \\
\hline 4. & 63 & 5 & $8 \%$ \\
\hline 5. & 67 & 2 & $4 \%$ \\
\hline 6. & 70 & 3 & $4 \%$ \\
\hline 7. & 73 & 1 & $12 \%$ \\
\hline 8. & 77 & 3 & $12 \%$ \\
\hline 9. & 80 & 1 & $12 \%$ \\
\hline 10. & 83 & 2 & $8 \%$ \\
\hline 11. & 87 & 1 & $12 \%$ \\
\hline 12. & 93 & 2 & $8 \%$ \\
\hline 13. & 97 & 1 & $4 \%$ \\
\hline & Jumlah & 25 & $100 \%$ \\
\hline
\end{tabular}




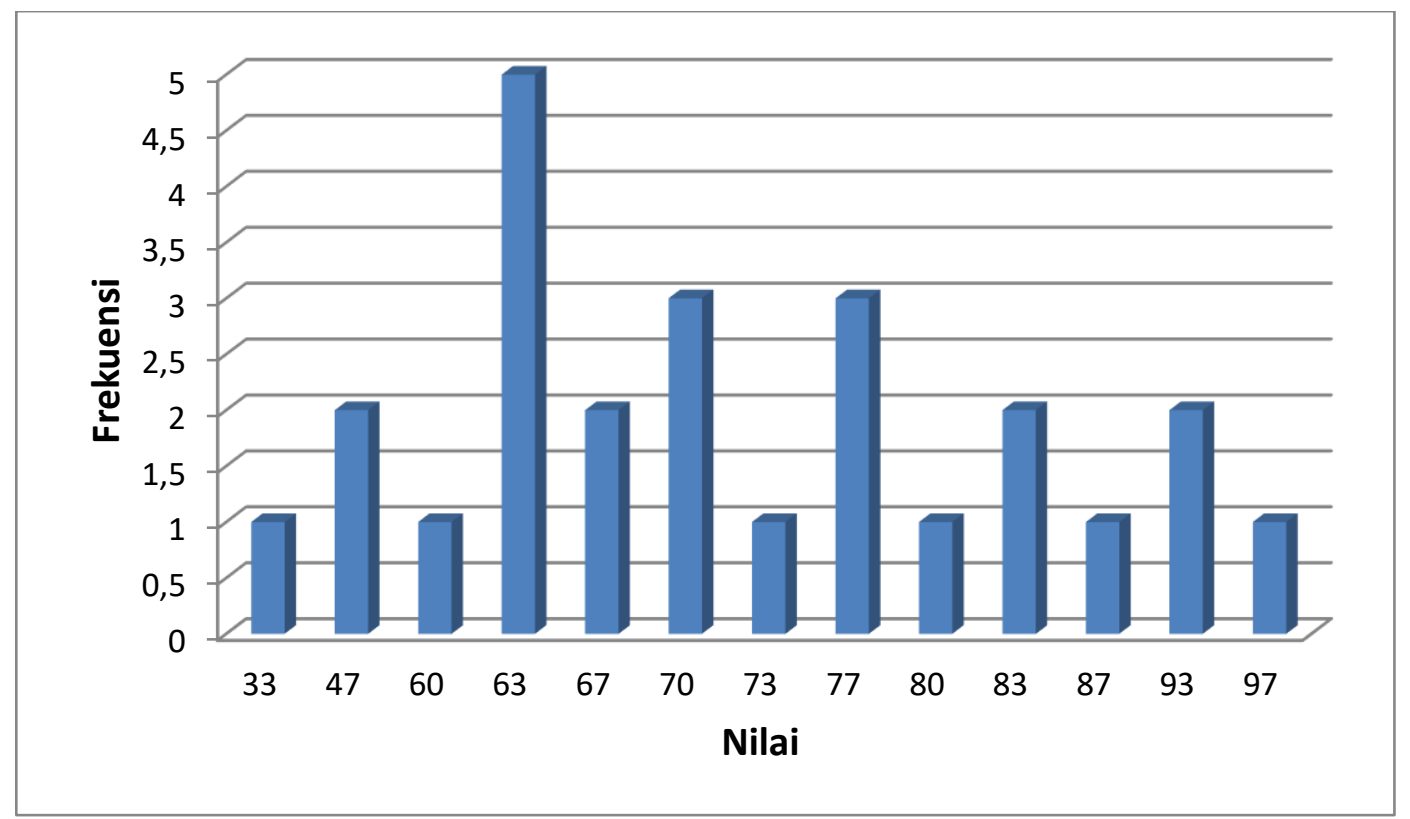

Gambar 6. Histogram Hasil Tes Akhir (Post Test) Kelas Kontrol 
Dari tabel 6 di atas dapat diperoleh informasi bahwa hasil nilai post test dari kelas kontrol di mana angka terendah memperoleh nilai terendah 33 dengan jumlah mahasiswa 1 orang dan nilai tertinggi 97 dengan jumlah 1 orang. Di mana nilai-nilai yang diperoleh dari 25 peserta dengan range mulai dari 33-97. Di mana modus atau nilai terbanyak yang diperoleh dari kelas kontrol mendapat nilai 63 dengan jumlah 5 orang.

\section{Tabel 7. Gabungan Hasil Pre-test dan Post test}

\begin{tabular}{|c|c|c|c|c|c|c|c|c|c|c|c|c|}
\hline \multirow[b]{2}{*}{ No } & \multicolumn{6}{|c|}{ Kelas Eksperimen } & \multicolumn{6}{|c|}{ Kelas Kontrol } \\
\hline & $\begin{array}{l}\text { Nilai } \\
\text { Pre } \\
\text { test }\end{array}$ & $\begin{array}{l}\mathbf{F} \\
\mathbf{r}\end{array}$ & $\mathbf{F x}$ & $\begin{array}{l}\text { Nilai } \\
\text { Post } \\
\text { test }\end{array}$ & $\mathbf{F r}$ & $\mathbf{F x}$ & $\begin{array}{l}\text { Nilai } \\
\text { Pre } \\
\text { test }\end{array}$ & $\mathbf{F r}$ & $\mathbf{f x}$ & $\begin{array}{l}\text { Nilai } \\
\text { Post } \\
\text { test }\end{array}$ & Fr & $\mathbf{f x}$ \\
\hline 1 & 17 & 1 & 17 & 33 & 1 & 33 & 30 & 1 & 30 & 33 & 1 & 33 \\
\hline 2 & 20 & 1 & 20 & 40 & 1 & 40 & 37 & 2 & 74 & 47 & 2 & 94 \\
\hline 3 & 27 & 3 & 81 & 43 & 1 & 43 & 60 & 1 & 60 & 60 & 1 & 60 \\
\hline 4 & 40 & 4 & 160 & 47 & 3 & 141 & 63 & 2 & 126 & 63 & 5 & 315 \\
\hline 5 & 43 & 1 & 43 & 53 & 1 & 53 & 67 & 1 & 67 & 67 & 2 & 134 \\
\hline 6 & 50 & 2 & 100 & 70 & 2 & 140 & 70 & 1 & 70 & 70 & 3 & 210 \\
\hline 7 & 53 & 1 & 53 & 73 & 1 & 73 & 73 & 3 & 219 & 73 & 1 & 73 \\
\hline 8 & 57 & 2 & 114 & 77 & 4 & 308 & 77 & 3 & 231 & 77 & 3 & 231 \\
\hline 9 & 60 & 2 & 120 & 80 & 2 & 160 & 80 & 3 & 240 & 80 & 1 & 80 \\
\hline 10 & 63 & 1 & 63 & 83 & 5 & 415 & 83 & 2 & 166 & 83 & 2 & 166 \\
\hline 11 & 67 & 1 & 67 & 87 & 1 & 87 & 87 & 3 & 261 & 87 & 1 & 87 \\
\hline 12 & 70 & 8 & 560 & 90 & 1 & 90 & 90 & 2 & 180 & 93 & 2 & 186 \\
\hline 13 & 73 & 1 & 73 & 93 & 2 & 186 & 97 & 1 & 97 & 97 & 1 & 97 \\
\hline 14 & 77 & 2 & 154 & 97 & 1 & 97 & & & & & & \\
\hline 15 & 80 & 1 & 80 & & & & & & & & & \\
\hline 16 & 83 & 3 & 249 & & & & & & & & & \\
\hline 17 & 90 & 1 & 90 & & & & & & & & & \\
\hline 18 & 93 & 1 & 93 & & & & & & & & & \\
\hline Jumlah & 1063 & 36 & 2137 & & & 1866 & 914 & 25 & 1821 & 930 & 25 & 1766 \\
\hline $\begin{array}{l}\text { Rata- } \\
\text { rata }\end{array}$ & & & 59.36 & & & 71.76 & & & 72.82 & & & 70.64 \\
\hline
\end{tabular}

Dari tabel 7 di atas diperoleh data bahwa terdapat kenaikan dari hasil rata-rata pre test dan post test di kelas eksperimen dan terdapat penurunan dari hasil rata-rata pre test dan post test di kelas kontrol. Hasil rata-rata yang diperoleh kelas ekperimen dari 59.36 menjadi 71.76 dan pada kelas kontrol dari 72.82 menjadi 70.64. Awal pre test di kelas eksperimen nilai tertinggi memperoleh nilai 93 dan saat post test naik menjadi 97 dengan 
frekuensi mahasiswa berjumlah 1 orang. Dan di kelas kontrol nilai tertinggi saat pre test dan post test yaitu 97 dengan jumlah frekuensi 1 mahasiswa.

Hal yang sama juga dihasilkan Hanum (2013) dalam penelitiannya yang menunjukkan bahwa pelaksanaan pembelajaran e-learning sebagai media pembelajaran di SMK Telkom Sandhy Putra Purwokerto cukup efektif dengan tingkat kecenderungan 77,27\%. Faktor-faktor yang menjadi pendukung dalam pelaksanaan e-learning di SMK Telkom Sandhy Putra Purwokerto antara lain: kesiapan SDM untuk meningkatkan pembelajaran e-learning, fasilitas software untuk mengembangkan media pembelajaran, fasilitas sarana internet di lingkungan sekolah, dan kebutuhan pelaksanaan media pembelajaran e-learning di SMK Telkom Sandhy Putra Purwokerto untuk meningkatkan dan menambah aktivitas pembelajaran di kelas.

\section{KESIMPULAN}

Terdapat kenaikan dari hasil pre test dan post test di kelas eksperimen dan penurunan dari hasil pre test dan post tes di kelas kontrol. Hasil rata-rata yang diperoleh kelas ekperimen dari 59.36 menjadi 71.76 dan pada kelas kontrol dari 72.82 menjadi 70.64 .

\section{DAFTAR PUSTAKA}

Hakim, Siti Nurina dan Aliffatullah Alyu Raj. 2017. Dampak Kecanduan Internet (Internet Addiction) pada Remaja. Prosiding Temu Ilmiah X Ikatan Psikologi Perkembangan Indonesia.

Hanum, Numiek Sulistyo. 2013. Keefektifan E-Learning Sebagai Media Pembelajaran (Studi Evaluasi Model Pembelajaran E-Learning SMK Telkom Sandhy Putra Purwokerto). Jurnal Pendidikan Vokasi, 3 (1), 90-102. Retrieved from https://journal.uny.ac.id/index.php/jpv/article/view/1584/1314

Haryanto, Agus Tri. Smartphone Jadi Pintu Masuk Orang Indonesia ke Internet. Retrieved from https://inet.detik.com/telecommunication/d-4552912/smartphone-jadi-pintumasuk-orang-indonesia-ke-internet. Diakses 19 Mei 2019.

Nurmalasari, N., \& Wulandari, D. (2018). Pengaruh Penggunaan Gadget Terhadap Tingkat Prestasi Siswa Smpn Satu Atap Pakisjaya Karawang. JITK (Jurnal Ilmu Pengetahuan 
Dan Teknologi Komputer), $3 \quad$ (2), 211-218. Retrieved from http://ejournal.nusamandiri.ac.id/index.php/jitk/article/view/350.

Muhson, Ali. Pengembangan Media Pembelajaran Berbasis Teknologi Informasi. Jurnal Pendidikan Akuntansi Indonesia, 8 (2), 1-10. Retrieved from https://journal.uny.ac.id/index.php/jpakun/article/view/949/759

Ratri, S., Bain, B., \& Amin, S. (2017). Pengaruh Penggunaan Media Pembelajaran Sejarah Indonesia E- Learning Berbasis Quipper School Terhadap Minat dan Hasil Belajar Siswa Kelas X SMK N 04 Kendal Tahun Pelajaran 2016/2017. Indonesian Journal of $\begin{array}{llll}\text { History } & \text { (2). } & \text { Retrieved } & \text { from }\end{array}$ https://journal.unnes.ac.id/sju/index.php/ijhe/article/view/19927

Sumardana, Made Dedy Sumardana. (2016). Pengembangan Media E-Learning Berbasis Schoology pada Mata Pelajaran IPA Kelas Viii Semester Ganjil Tahun Pelajaran 2016/2017 di Smp Saraswati Singaraja. e-Journal EdutechUniversitas Pendidikan $\begin{array}{lllll}\text { Ganesha, } & 5 & \text { (2). } & \text { Retrieved }\end{array}$ https://ejournal.undiksha.ac.id/index.php/JEU/article/view/8534/5574

Sumiharsono, M. Rudy dan Hisbiyatul Hasanah. 2017. Media Pembelajaran. Jember: Pustaka Abadi. 